\title{
Hacer las reglas del hacer: concepciones y rutinas bibliotecarias en los reglamentos de las bibliotecas populares en la Argentina (1870-1875)
}

\section{Fazer as regras do fazer: Concepções e rotinas bibliotecárias nos regulamentos das bibliotecas populares na Argentina (1870-1875)}

\section{Making the rules for doing: conceptions and library routines in the regulations of the public libraries in Argentina (1870-1875)}

Javier Planas

\begin{abstract}
Resumen
El artículo aborda los vínculos sostenidos por la Comisión Protectora de las Bibliotecas Populares y las bibliotecas populares con relación a la elaboración de reglas adecuadas para ordenar el funcionamiento de estas instituciones. A partir de un análisis del Boletín de las Bibliotecas Populares, se estudia la manera en que la Comisión insistió en la difusión de dos servicios: la lectura gratuita en la sala y el préstamo domiciliario de libros a cambio de una cuota accesible. Se observa cómo las bibliotecas incorporaron progresivamente esas pautas $\mathrm{y}$, al hacerlo, colaboraron con sus propios reglamentos con la estrategia pedagógica del Boletín. Se examinan, asimismo, las indicaciones técnicas presentes en la revista para contribuir con el desarrollo de los procesos bibliotecarios necesarios para sustentar dichos servicios. Se concluye que entre 1870 y 1875 estas acciones renovaron la tradición bibliotecaria en la Argentina, aun cuando es posible detectar diversas deficiencias y contrasentidos en la transmisión de esta nueva concepción bibliotecológica. Finalmente, se evalúa la pertinencia de los reglamentos y otros documentos institucionales para desenvolver los estudios históricos sobre los contextos de la lectura.
\end{abstract}

Palabras Claves: Historia de las bibliotecas; Historia de la Lectura; Bibliotecas Populares; Prácticas bibliotecarias; Reglamentos de bibliotecas; Préstamo de libros

\footnotetext{
* Magister en Ciencias Sociales. Docente del Departamento de Bibliotecología de la Universidad Nacional de La Plata, Argentina. E-mail: planasjavier@yahoo.com.ar
} 


\title{
Resumo
}

A pesquisa aborda os vínculos sustentados pela Comissão Protetora de Bibliotecas Populares e as Bibliotecas Populares, com relação à elaboração de regras adequadas para organizar o funcionamento destas Instituições. A partir da análise da Revista "Boletin", estuda-se a maneira em que a Comissão incentivou a difusão de dois serviços: a) a leitura gratuita na entidade; e b) o empréstimos domiciliar de livros em troca de uma taxa acessível. Observase como as bibliotecas foram incorporando essas pautas, e ao realizá-las, colaboraram com seus próprios regulamentos com a estratégia pedagógica da publicação. Da mesma maneira, examinam-se as orientações técnicas presentes na revista para contribuir com o desenvolvimento dos processos bibliotecários necessários para sustentação destes serviços. Conclui-se que entre 1870 e 1875 estas ações renovaram a tradição bibliotecária na Argentina, ainda quando possível a deteç̧ão de diversas deficiências e contradições na transmissão desta nova concepção de biblioteconomia. Finalmente se avalia a pertinência dos regulamentos e outros documentos institucionais para desenvolver os estudos históricos sobre os contextos da leitura.

Palavras-chaves: História das bibliotecas; História das leituras; Bibliotecas Populares; Práticas bibliotecárias; Regulamentos de Bibliotecas; Empréstimos de Livros.

\begin{abstract}
The assay addresses the links supported by the Comisión Protectora de las Bibliotecas Populares and public libraries, in relation to the development of appropriate rules for arranging the operation of these institutions. From an analysis of the Bulletin of Popular Libraries, we studied the ways in which the Comisión insisted in the diffusion of two services: free reading room and home loan of books in exchange for an affordable fee. It is observed how libraries gradually incorporated these rules, and in doing so, they contributed with their own regulations to the pedagogical strategy of the Bulletin. Also we examined the technical instructions present in the Bulletin in order to contribute to the development of library processes necessary to support these services. It is concluded that between 1870 and 1875 these actions renewed the library tradition in Argentina, although it is possible to detect some deficiencies and contradictions in the transmission of this new conception of librarianship. Finally, the relevance of regulations and other institutional documents are evaluated to develop historical studies about the contexts of reading.
\end{abstract}

Keywords: History of Libraries; History of Reading, Public Libraries, Library Practices, Library Regulations; Loan 


\section{Introducción}

No cabe duda que 1870 fue un año clave para las bibliotecas populares en la República Argentina. La fecha remite a la sanción de la ley 419 de protección y fomento a estas instituciones, al cierre de una etapa en los trabajos de Domingo Faustino Sarmiento sobre el asunto y al inicio de una tradición bibliotecaria que el paso del tiempo enriqueció con nuevas experiencias y perspectivas. La normativa adoptada por el gobierno nacional de aquel entonces generaba un modelo de gestación sustentado en las acciones de la sociedad civil. Como estímulo el Estado ofrecía una subvención igual al dinero recolectado por cada asociación, tramitar la inversión de ambas contribuciones en libros y hacer el envío del material sin costo adicional. La autonomía administrativa de las bibliotecas y la libre elección de las obras constituían una clave fundamental, no sólo porque estas cualidades suponían un atractivo para las asociaciones, sino también porque el gobierno alivianaba las cargas presupuestarias en el área de instrucción pública mediante la delegación de las funciones organizativas en las sociedades. La simplicidad del sistema, las gestiones de la Comisión Protectora de las Bibliotecas Populares (en adelante, la Comisión) y la buena recepción que tuvo la política en la sociedad alentó un importante movimiento bibliotecario entre 1870 y 1875 , superando el centenar de subvenciones otorgadas. ${ }^{1}$ La conformación de una extensa red de bibliotecas que pudiera servir a las sucesivas generaciones de lectores que emergía de las campañas de alfabetización parecía consolidarse a mitad de la década. ${ }^{2}$ Pero poco tiempo después, estas instituciones comenzaron a transitar un período de progresiva decadencia, sin duda disparado por la disolución de la ley de fomento, la supresión de la Comisión y la suspensión de los subsidios para las asociaciones. Las bibliotecas organizadas hasta entonces se fueron disolviendo $\mathrm{y}$,

1 SABOR RIERA, María Ángeles. Contribución al estudio histórico del desarrollo de los servicios bibliotecarios de la Argentina en el siglo XIX. Resistencia: Universidad Nacional del Nordeste, Dirección de Bibliotecas, 1974-1975, $2 \mathrm{v}$.

2 La Comisión entendía que el público de las bibliotecas estaba conformado por dos tipos de lectores: de un lado, aquellos que por su capital social y cultural estaban en condiciones de cumplir con los pasos necesarios para fundar y sostener una institución; de otro, un conjunto de lectores recién llegados al campo de la lectura, cuyo acceso al mundo del libro quedaría asegurado por estas asociaciones, especialmente en aquellas zonas donde el comercio de impresos era prácticamente inexistente. Para una ampliación sobre esta distinción, puede consultarse: PLANAS, Javier. "Bibliotecas populares en la Argentina Decimonónica. Aproximaciones críticas a una política de la lectura" [en línea]. Actas de la I Jornadas de intercambio y reflexión acerca de la investigación en bibliotecología. La Plata: Facultad de Humanidades y Ciencias de la Educción, Departamento de Bibliotecología, 2010. Disponible en Word Wide Web: http://jornadabibliotecologia.fahce.unlp.edu.ar/jornada-2010/planas [citado: 9 dic 2013] 
según los informes disponibles, hacia 1894 quedaban poco menos de una veintena de bibliotecas populares. ${ }^{3}$

Durante los años prolíficos de esta política de lectura, la Comisión procuró instituir nuevas maneras de entender y organizar las rutinas bibliotecarias a través de la publicación del Boletín de las Bibliotecas Populares. ${ }^{4}$ Una parte fundamental de su proyecto cultural estaba comprometida con esa transformación conceptual y operativa. Y para producir tal renovación transmitieron desde las páginas de la revista dos pautas fundamentales: la primera de ellas consistía en mostrar cuál era la "esencia" de las bibliotecas populares; la segunda lección estaba orientada a sentar las bases funcionales de esa esencia, centrándose en la institucionalización del servicio de préstamo de libros a domicilio, una cuestión que cambiaría sustancialmente la incipiente historia de las bibliotecas de la Argentina.

En un sentido general, la Comisión trabajó su estrategia mediante algunas notas críticas y principalmente a través de la reproducción de reglamentos pertenecientes a las bibliotecas populares que por entonces se encontraban en funcionamiento. Este modo particular de cimentar las reglas del hacer bibliotecario, conjuntamente con las pautas que brindan otros documentos, permiten una aproximación a lo que fueron estas instituciones y a la idea de lo que debían ser. Un análisis de este tipo obliga a considerar estas fuentes como representaciones de un tiempo bibliotecario singular, así como también visualizar las continuidades y las rupturas que a partir de ellas es posible entrever con la tradición instituida. ${ }^{5}$ Esta misma calidad ofrece, entonces, un pasaje hacia el estudio de la Historia de la Lectura, ${ }^{6}$ cuyo objeto todavía se encuentra inscripto en una rica tensión disciplinar. ${ }^{7}$

3 TRIPALDI, Nicolás. "Indicadores de crisis: el caso de las bibliotecas populares argentinas". XXV Reunión Nacional de Bibliotecarios: la biblioteca y los bibliotecarios en tiempos de crisis. Buenos Aires: ABGRA, 1991, p. 1-11

4 Boletín de las Bibliotecas Populares, Buenos Aires, Comisión Protectora de las Bibliotecas Populares, 1872$1875, \mathrm{n}^{\circ} 1-6$.

5 PARADA, Alejandro E. "En busca de los reglamentos perdidos". El Dédalo y su ovillo. Ensayos sobre la palpitante cultura impresa en la Argentina. Buenos Aires, Instituto de Investigaciones Bibliotecológicas, Facultad de Filosofía y Letras, Universidad de Buenos Aires, 2012, pp. 191-225.

6 DENIPOTI, Cláudio. "Decência imperial, silêncio republicano: normas e gestualidades da leitura em regimentos e estatutos de bibliotecas (1821-1918)". Varia Historia, 2007, vol. 23, n 38, pp. 597-614.

7 Aportes como los de Roger Chartier, Robert Darnton, Carlo Ginzburg y Armando Petrucci, entre otros referentes del campo, han contribuido decisivamente a estimular esta área de investigaciones. Estos trabajos y los debates que le son inherentes han encontrado una buena acogida en América Latina. En países como Argentina, Brasil, Chile, Colombia y México se produjo en las últimas dos décadas un valioso número de intervenciones relativas a diversos nudos problemáticos, a saber: la constitución de los públicos lectores, la comprensión de las prácticas de lecturas, la circulación de los libros y otros impresos, la conformación de figuras autoriales, la institución de los mercados editoriales y la organización de distintos 
Dado ese modelo de elaboración pedagógica que la Comisión propuso con el Boletín, donde las secciones de su autoría se entrecruzan con los materiales elaborados por las mismas bibliotecas, resulta oportuno retomar la distinción teórica propuesta por Michel de Certeau entre tácticas y estrategias para comprender el modo en que se produjo aquella renovación bibliotecaria. ${ }^{8}$ En tal sentido, entendemos que el organismo oficial de las bibliotecas se sitúa en el polo de las estrategias. Esta condición le es propia porque se trata un lugar dotado de institucionalidad, con capacidad para producir un discurso con cierta autonomía y con la disponibilidad legalmente adquirida para ejercer el poder de control sobre el campo de destinatarios al que se orienta. En el polo de las tácticas se ubican las bibliotecas populares, cuya voluntad de acción está limitada a un orden ajeno. Esa voluntad es apreciable en términos de "maneras de hacer".

Tomando como referencias las coordenadas precedentes, este artículo propone un recorrido analítico por los entresijos bibliotecológicos que contribuyeron a generar una trasformación en el campo de las bibliotecas hacia finales del siglo XIX en la Argentina. Se hace hincapié en el establecimiento de la lectura en la sala, en la institución del préstamo de libros a domicilio y la transmisión de pautas para llevar adelante los diversos procesos que sustentan el desarrollo de estos servicios.

\section{"La esencia de una biblioteca popular"}

Los reglamentos de las bibliotecas populares no son todos iguales. No obstante, en sus puntos angulares son coincidentes, incluso se expresan en idénticos términos. Este último aspecto, sin duda, es el resultado de la política pedagógica sostenida por la Comisión. Las bibliotecas que se organizaron luego de la aparición de los dos primeros números del Boletín hicieron suyas las reglamentaciones que se proponían como modelos, aunque siempre con algunas variantes. Estas diferencias están dadas principalmente por el mayor o menor nivel de descripción utilizado para ordenar las prácticas.

tipos de bibliotecas y gabinetes de lectura, entre otros aspectos.

8 De Certeau, Michel. La invención de lo cotidiano: I. Artes de hacer. México: Departamento de Historia, Universidad Iberoamericana, 2000 [1990], p. 229

9 Puede consultarse una versión ampliada de esta sección del ensayo en: PLANAS, Javier. "La esencia de una biblioteca popular. Una polémica de sobre los lectores y las modalidades de acceso a la lectura” [en línea]. Actas de II Jornadas de intercambio y reflexión acerca de la investigación en bibliotecología. La Plata: Facultad de Humanidades y Ciencias de la Educción, Departamento de Bibliotecología, 2011. Disponible en Word Wide Web: http://jornadabibliotecologia.fahce.unlp.edu.ar/actas-2011/bibliotecas-lectores/planas-la-esencia [citado: 9 dic 2013] 
Por ejemplo, mientras que el reglamento de la Biblioteca Popular de Chivilcoy de 1872 prevé seis artículos para regular las lecturas públicas, ${ }^{10}$ la mayoría de las bibliotecas le dedican entre una y dos cláusulas. Las semejanzas que se extienden entre los distintos reglamentos están ligadas a las condiciones de acceso a la lectura ofrecidas por las bibliotecas populares. El espíritu que impera en estos ordenamientos procura un acercamiento más intenso entre los lectores y el material bibliográfico. En este sentido, el préstamo domiciliario de los libros constituye la innovación bibliotecológica más radical que implementaron estas instituciones respecto de la aún incipiente tradición bibliotecaria de la Argentina. Hasta ese momento, solamente los gabinetes de lectura ofrecían esta variante a cambio de un alquiler. De hecho, la importante expansión de estos locales en áreas metropolitanas como Buenos Aires limitó el desarrollo de los servicios de las bibliotecas públicas en la primera mitad del siglo XIX. ${ }^{11}$

La ley nacional de protección a las bibliotecas populares y el decreto que la acompaña no son explícitos respecto de la obligatoriedad del préstamo domiciliario. No obstante, la introducción de este novedoso servicio es para la Comisión una condición que se impone como requisito para la aprobación de los subsidios. Esta exigencia primordial se instituye desde la definición de biblioteca popular, que la describe como "una reunión de libros mas ó menos considerable, puesta en un local cualquiera, al cuidado de una persona, con el objeto de facilitar dichos libros en préstamo, bajo ciertas condiciones y garantías, á cualquier vecino que quiera leerlos". ${ }^{12}$ Los miembros de la Comisión no se limitaron a esta declaración de intenciones y alcances. El predicamento oficial avanzó sobre la crítica y la reproducción de las pautas reglamentarias ajustadas a su concepción bibliotecaria.

Un ejemplo interesante puede verse en el primer número del Boletín, donde aparece un severo llamado de atención para la Sociedad Tipográfica Bonaerense. El motivo de esta advertencia se concentra en la manera en que esta asociación administraba la biblioteca que mantenía para sus afiliados. Sin ningún tipo de rodeo retórico, los miembros de la Comisión cargan contra lo que consideran una inapropiada política bibliotecaria y, por extensión, contra el modelo institucional que aún proyectaba la Biblioteca Pública

10 Boletín, op. cit., $1872, n^{\circ}$ 2, pp. CV-CVI. También publicado en: Biblioteca Popular de Chivilcoy, n 1, 1872, pp. 25-27.

11 PARADA, Alejandro E. Los libros en la época del Salón Literario. El Catálogo de la Librería Argentina de Marcos Sastre (1835). Buenos Aires: Academia Argentina de Letras, 2008, p. 456

12 Boletín, op. cit., $1872, \mathrm{n}^{\circ} 1$, pp. XII. 
de Buenos Aires por aquel entonces. ${ }^{13}$ Recuperemos el fragmento medular de la crítica:

La «Sociedad Tipográfica Bonaerense» tiene desde hace algunos años, un plantel de Biblioteca para el uso de sus socios i de las personas presentadas por ellos ;- pero tiene el gravísimo inconveniente de no ser circulante. El reglamento de esta Biblioteca está calcado sobre el prolijamente restrictivo é inquisitorial de la Biblioteca Pública que mantiene el Gobierno de Buenos Aires. A ciertas horas, por la noche, se abre la biblioteca, que debe ofrecer menos atractivo para jentes que trabaja todo el día, que los cafées y los teatros, i hai necesidad de ir al Salon de lectura á consultar un libro en silencio, debiendo saberse previamente de memoria el reglamento, que no puede ser mas inadecuado para una sociedad de esta clase. Baste decir que no se puede llevar un libro cualquiera á domicilio, ni aun dejando recibo ni garantía para su devolucion en cierto plazo, que es lo que constituye la esencia de una Biblioteca Popular. ${ }^{14}$

La cita no deja dudas sobre la posición que toma la Comisión acerca de la idea de servicio que mantiene la biblioteca porteña. Desde su fundación en los años de la revolución hasta la década de 1870, esta institución retenía aún las ideas bibliotecarias propias de la Ilustración. El principal interés no se apoyaba tanto en la difusión del conocimiento, sino más bien en la conservación de los libros y en los usos académicos de los mismos. ${ }^{15}$ La Comisión hace un esfuerzo por despegarse de esta concepción. En este desplazamiento crítico, "la esencia de una Biblioteca Popular" está conformada por una idea de acceso democrático al saber, de un lado, y por una renovada manera de entender la función de la biblioteca como intermediario entre los lectores y los libros, de otro.

En el número siguiente del Boletín, los redactores felicitan abiertamente a los "hombres laboriosos, morales y de buen sentido" de la Sociedad Tipográfica Bonaerense por haber recogido la crítica y modificado el reglamento de la biblioteca. Esta apertura le permitió a la entidad recibir las subvenciones del Estado, un objetivo que sus miembros habían buscado desde la promulgación de la Ley $419 .{ }^{16}$

13 Para una bibliografía mínima pero básica sobre la historia de la Biblioteca Pública de Buenos Aires durante el siglo XIX remito los siguientes trabajos: Groussac, Paul. Historia de la Biblioteca Nacional. Buenos Aires: Biblioteca Nacional, 1967 [1893], p. 67; GonzÁLEz, Horacio. Historia de la Biblioteca Nacional. Estado de una polémica. Buenos Aires: Biblioteca Nacional, 2010, p. 336; PARADA, Alejandro E. Los orígenes de la biblioteca pública de Buenos Aires. Antecedentes, prácticas, gestión y pensamiento bibliotecario durante la Revolución de Mayo (1810-1826). Buenos Aires, Instituto de Investigaciones Bibliotecológicas, Facultad de Filosofía y Letras, Universidad de Buenos Aires, 2009, p. 343; SABOR Riera, María Ángeles, op. cit.

14 Boletín, op. cit., 1872, no. 1, p. LI-LII

15 PARADA, Alejandro E. Los orígenes, op. cit.

16 BADozA, María Silvia. “Los tipógrafos en Buenos Aires. La sociedad tipográfica bonaerense (1855-1880)”. Mercado de trabajo y paro forzoso: desde los comienzos de la Argentina moderna hasta la crisis de los años 
Tomar distancia de lo que representaba simbólicamente y de hecho la Biblioteca Pública de Buenos Aires es, entonces, instituir nuevas significaciones respecto de lo que es o podría ser una biblioteca. Estos sentidos que la Comisión transmite desde su revista estaban trabajados para un presente cultural en el que nuevos lectores comienzan a modificar lenta pero progresivamente el campo de la lectura. ${ }^{17}$ En otras palabras, los redactores del Boletín eligen muy bien contra que oponerse para dotar de "esencia" a las bibliotecas populares. Incluso los dichos de Vicente Quesada, por entonces Director de la biblioteca porteña, son útiles a los efectos buscados por la Comisión. En un breve informe de gestión que se publica en el sexto número de la revista, Quesada observa:

Como Vd. sabe, la Biblioteca de Buenos Aires está destinada á proporcionar al estudioso i al erudito los medios de instrucción sin gasto; por eso adquiero con preferencia aquellas obras que, por su costo no están al alcance de la generalidad de los particulares. Destinada al desarrollo científico del país, es un centro de estudio, no de mero entretenimiento. Esas obras no pueden salir del establecimiento, diferenciándose en este punto de las Bibliotecas populares i del sistema de Bibliotecas de préstamo tan generalizado en Alemania.

Si el número de lectores no es crecido, es de provecho i utilidad: son personas que se consagran á estudios sérios, á indagaciones científicas los que lo frecuentan generalmente..$^{18}$

La distancia que se impone entre una concepción de biblioteca y otra está fundamentada en el tipo de público al que cada una pretende alcanzar. Quesada claramente le atribuye a la Biblioteca Pública las funciones que por entonces tenían las bibliotecas nacionales europeas. Este cambio de jerarquía y finalidad formaban parte del proyecto institucional que se propuso llevar adelante como Director. Son testimonio de ello dos publicaciones: Las bibliotecas europeas y algunas de América Latina ${ }^{19} \mathrm{y}$ La Biblioteca Pública de Buenos Aires: proyecto de reorganización..$^{20} \mathrm{El}$ primero de los trabajos, que es el que nos interesa destacar, reúne y compara los

\footnotetext{
30, 1990, nº 3, t. 2, p.7-41

17 PRETo, Adolfo. "Configuración de los campos de lectura, 1880-1910". El discurso criollista en la formación de la Argentina moderna. Buenos Aires: Siglo XIX, 2006 [1988], pp. 23-82.

18 Boletín, op. cit., 1875, no. 6, p. 206.

19 QUESADA, Vicente. Las bibliotecas europeas y algunas de América Latina: con un Apéndice sobre el Archivo General de Indias en Sevilla, la Dirección de Hidrografía y la Biblioteca de la Real Académica de la Historia en Madrid. Buenos Aires: Imprenta y Librerías de Mayo, 1877, p. 651

20 QUESADA, Vicente. La Biblioteca Pública de Buenos Aires: proyecto de reorganización. Buenos Aires: Imprenta de Biedma, 1879, p. 43
} 
aspectos administrativos de establecimientos como la Biblioteca Nacional de Francia, la Biblioteca del Museo Británico y la Biblioteca Real de Munich, entre otros semejantes. Este sesgo motivó una fuerte respuesta de Sarmiento, ${ }^{21}$ que de forma coherente con su trayectoria en el área, criticó el énfasis que el autor había puesto en las restricciones al uso del material bibliográfico. ${ }^{22}$

En rigor, debemos indicar que ambos imaginaban de modos muy distintos los horizontes de la Biblioteca Pública de Buenos Aires. Para el primero, el camino a seguir era el modelo norteamericano, esto es: un establecimiento abierto a todos, provisto de un sistema de préstamo a domicilio, consulta en sala y con una cobertura amplia de temas y de tipos de lectura. Para el segundo, el futuro de la biblioteca que nació con la revolución de mayo era convertirse en una institución nacional, cuyas prioridades serían el desarrollo del conocimiento científico y literario, junto con la conservación de los fondos documentales. La discusión quedará zanjada cuando Buenos Aires se transforme en capital de la República Argentina en 1880 y la biblioteca adquiera el estatuto de "nacional" que ostenta en la actualidad.

Lo que enseña la tensión entre estas dos fuertes personalidades de la cultura, más allá del problema que suscitaba el devenir de la Biblioteca, es la densidad del proyecto bibliotecario que encarnaban las bibliotecas populares. Alcanzar un nuevo público, amplio desde el punto de vista cuantitativo, diverso en lo que respecta a sus formas culturales y disperso en términos territoriales, exigía poner en acto una renovación del campo bibliotecario. Y es en este punto donde las maneras de hacer constituyen la piedra angular de una política de la lectura como la que se propuso la Comisión. Diseminar el servicio de préstamo a domicilio - hoy naturalizado por todos los usuarios de las bibliotecas-, requería en aquel momento un esfuerzo estratégico de producción discursiva. El Boletín es el lugar a la vez que el testimonio tangible de esta apuesta.

21 La réplica apareció en dos artículos: (1) SARmiEnto, Domingo F. Bibliotecas Europeas y algunas en América Latina, por Vicente Quesada, Director de la Biblioteca de Buenos Aires. La Educación Común, 1877, t. 2, nº 7, p. 207-219. (2) Sarmiento, Domingo F. Cuestión de bibliotecas. La Educación Común, 1877, t. 2, nº 8, p. 239-248.

22 Para una lectura bibliotecológica de esta polémica: PlanAs, Javier, La esencia, op. cit. Para una interpretación situada en torno a las concepciones sobre la lectura en el pasaje de la década de 1870 a la de 1880 : Batticuore, Graciela. "Libros, lectores y bibliotecas en la encrucijada del Progreso". Laera, Alejandra (dir.). Historia crítica de la literatura Argentina. El brote de los géneros. Buenos Aires: EMECÉ, 2010, pp. 413-440. 


\section{Los libros fuera de la biblioteca: las formas del préstamo a domicilio}

Vamos a explorar las reglas del hacer bibliotecario inscriptas desde el primer número del Boletín. En el anexo de esta entrega se publican dos reglamentos. El primero de estos documentos corresponde a la Biblioteca Popular del Club Casino de Catamarca. En este registro, las referencias a la circulación de los libros son de carácter general, sin mayores detalles. La pauta central establece que la lectura es gratuita en la biblioteca para cualquier persona del pueblo, mientras que el préstamo a domicilio se estima por el término de ocho días a cambio de una módica suma de dinero a pagar por anticipado. Esta apertura democrática que se establece como principio fundante no se confirma en los aspectos operativos del servicio -o se resuelve de mala manera-. Por medio de una de las cláusulas fundamentales del procedimiento de préstamo, se advierte: "El Bibliotecario no podrá entregar obra ni publicación alguna, para ser llevada a domicilio, sinó á persona conocida ó que le dé suficiente garantía, i será responsable de todo cuanto se estravie". ${ }^{23}$ La cita permite apreciar cómo, cuando resulta complejo fijar un criterio, es el reglamento mismo el que evidencia las indeterminaciones del hacer. En otras palabras: en el terreno aparentemente cerrado del orden reglamentario no sólo encontramos las representaciones de las prácticas, sino también los indicios de su fluidez. En este caso, la elasticidad de lo que puede ser o no "suficiente garantía" deja al bibliotecario amplios márgenes de acción. No obstante, la amenaza sobre las posibles consecuencias de una mala elección echa alguna duda sobre la pluralidad del servicio. Al pasar por alto esta ambigüedad, los miembros de la Comisión pudieron legitimar rutinas selectivas que se oponen a las ideas sustanciales de su propia perspectiva bibliotecológica. Este descuido tendrá resonancias en los números posteriores del Boletín, en los que hay aclaraciones respecto de estos tópicos.

El segundo reglamento pertenece a la Biblioteca Popular de Chivilcoy fundada en $1866 .{ }^{24} \mathrm{El}$ origen de este documento, según es posible constatar en Anales de la Educación Común, ${ }^{25}$ es el producto de una combinación de dos fuentes: por un lado, la traducción que Juana Manso hiciera expresamente para la ocasión del reglamento de una biblioteca popular de New York; por

23 El Boletín, op. cit., 1872, n 1, p. 105. También publicado en: Club Casino de Catamarca. Estatutos del Club Casino de Catamarca y su Biblioteca. 2ed. Catamarca: Imprenta del Pueblo, 1871, p. 14

24 El Boletín, op. cit., 1872, nº, pp. 107-111

25 Biblioteca de Chivilcoy. Anales de la Educción Común, 1866, vol. IV, nº 42, pp. 140-144. 
otro, las disposiciones y los estatutos de la biblioteca popular de San Juan, inaugurada en la misma época. El registro resultante es más escueto en su desarrollo global que el de la biblioteca catamarqueña que describimos más arriba, pero brinda mayores precisiones sobre el préstamo de libros. Este efecto de complementariedad seguramente influyó en la decisión editorial de la Comisión, que optó por incluir estas dos opciones antes que elaborar un modelo abstracto.

Entre las once disposiciones que reglan las rutinas de la biblioteca chivilcoyense, cinco artículos y varios incisos están dedicados a la circulación de los libros a domicilio. Las primeras cláusulas estipulaban la gratuidad de la lectura en el establecimiento y a domicilio para todos los habitantes de la ciudad. Los lectores no estaban obligados a contribuir solidariamente con la sociedad. Esta es una diferencia importante en términos de acceso respecto de la política de la biblioteca del Club Casino de Catamarca, pero a la vez significaba asumir un riesgo en relación a las fuentes de manutención de la asociación. Concretamente, el reglamento establecía cuatro condiciones para el préstamo a domicilio: (1) un volumen por vez; (2) las multas impagas inhabilitaban para nuevos préstamos; (3) los menores debían estar respaldados por sus padres o tutores, y (4) el número de lectores no podía exceder al de los libros, en cuyo caso sólo se entregaría un ejemplar por familia. El bibliotecario era responsable de la gestión del servicio. Esta persona estaba a cargo de fijar el período de la cesión - nunca mayor a 28 días-e inscribir los datos del solicitante y de la obra en el libro de préstamo. Asimismo, le correspondía administrar las posibles renovaciones, organizar la lista de reservas y controlar el cumplimiento de los plazos y el estado en que el material regresaba a los estantes. Ante cualquier contravención en la que incurrieran los lectores, el bibliotecario estaba obligado a informar lo sucedido a la comisión directiva y anotar la infracción en un registro especial. El dispositivo disciplinario de sanciones contemplaba multas para los casos de daños parciales y retraso en la devolución del material, y reintegro total de la obra por pérdida o destrucción. Cuando el libro no retornaba a la biblioteca en el doble del tiempo estipulado, la sociedad quedaba facultada para iniciar acciones legales.

Tras la efímera vida de esta biblioteca, una nueva comisión se propuso rehacer la experiencia seis años después. Lo interesante del caso es que los flamantes organizadores no hicieron uso del reglamento producido en su propio pueblo, aun cuando la primera entrega del Boletín avaló su pertinencia bibliotecológica. Esta reorientación invita a pensar en los usos que las bi- 
bliotecas hicieron de los consejos de la revista y en cómo estas utilizaciones singulares operaron silenciosamente sobre la publicación. Si bien es cierto que los redactores siempre seleccionaron el material de edición, su apuesta a elaborar un relato a partir de la trayectoria de estas asociaciones los colocaba en un plano más permeable a la mutua influencia (aunque ésta sin duda fuera desigual). Si se observan las disposiciones preparadas en 1866 y las de 1872, se podrá apreciar que la esencia de ambas propuestas se orienta hacia el mismo objetivo: facilitar el acceso a la lectura. El modelo operativo de este acceso también es semejante: los libros disponibles en la sala de lectura y para el préstamo a domicilio. Los procedimientos formales para conciliar esas dos pautas son, sin embargo, diferentes. Señalemos un ejemplo: la sección disciplinar del texto de 1866 detallaba hasta la multa que debía pagar el lector por cada mancha que tuviera el libro; en las normativas de 1872 apenas hay media docena de líneas dedicadas a estos aspectos. La divergencia más significativa que introduce el segundo reglamento en relación a la salida de libros es la adopción de una modesta cuota mensual o por préstamo. Si los miembros de la Comisión están en lo cierto cuando informan que el primer proyecto de biblioteca en Chivilcoy tuvo dificultades para renovar sus colecciones y por lo tanto para asegurar su vida útil, puede que esta nueva modalidad administrativa constituyera en sí una relectura del pasado reglamentario reciente.

En el cuarto número de la revista, y a modo de introducción de los reglamentos de las bibliotecas de Baradero y Humahuaca, los redactores observan algo preocupados la siguiente situación:

...en algunos reglamentos hemos visto la prohibición de pedir libros para leerlos en domicilio, lo que es contrario al espíritu de la institución, que ante todo se propone el fomento de la instrucción en todas las clases, crear el hábito de la lectura y poner el libro al alcance de todos, siéndoles á muchos indudablemente mas cómoda y provechosa la lectura en su domicilio, alrededor de su familia ó de sus amigos. ${ }^{26}$

Estamos una vez más ante la idea bibliotecológica central que sostiene la Comisión. Esta idea tiene una faz conceptual, identificada con la propuesta de un acceso amplio y democrático a la lectura, y una faz operativa, vinculada al desarrollo del préstamo de libros a domicilio. Estas dos caras son inseparables en la perspectiva de trabajo que fomenta el Boletín, a la vez que indisociables de un horizonte imaginario de la lectura: el libro es compañía en el hogar, se disfruta en la intimidad de la familia y de los amigos.

26 Boletín, op. cit., $1873, n^{\circ}$ 4, p. LXXXV 
En la continuidad del relato, los responsables de la revista introducen por primera vez de su autoría dos disposiciones adaptables a cualquier reglamento. Aunque presentadas tipográficamente como si fueran artículos, se trata en rigor de instrucciones que fijan un destino a la vez que admiten grados de movilidad en las futuras utilizaciones:

$1^{\circ}$-Acceso libre de todo el vecindario á los salones de la biblioteca en los días y horas para el servicio público.

$2^{\circ}$-Préstamo de los libros á domicilio á los sócios y estraños de la biblioteca, mediante ciertas restricciones, ya sea del tiempo durante el cual aquellos podrán estar en manos de una misma persona, sea respecto de la remuneración siempre módica, que el solicitante deberá satisfacer por este servicio en beneficio de la biblioteca. ${ }^{27}$

Esta medida adoptada por la Comisión constituye otra advertencia a los lectores del Boletín respecto de las prestaciones que debe brindar una biblioteca popular. Este énfasis, sin embargo, se desvanece en las incongruencias en las que suelen caer los redactores al seleccionar el material de edición. Como se puede apreciar en el fragmento precedente, el préstamo a domicilio se establece claramente para "sócios y estraños de la biblioteca". Siguiendo esta pauta, se alinea correctamente el reglamento de la biblioteca de Baradero, que estipula una suscripción social mensual y una cuota por cesiones ocasionales para quienes no estuvieran afiliados. El caso de Humahuaca es distinto, pues allí sólo los asociados estaban habilitados para llevar los libros a sus casas. Este descuido involuntario, que finalmente erosiona la coherencia discursiva de la revista, vuelve sobre ella como nuevos llamados de atención hacia los lectores.

En el último número del Boletín, la publicación del reglamento de la Biblioteca Popular de Nueve de Julio viene precedida de un comentario crítico acerca de las condiciones del préstamo a domicilio. El señalamiento se ubica justamente en el intersticio abierto por los contrasentidos observados anteriormente. Los miembros de la Comisión objetan a las asociaciones que el servicio sólo funcione para sus asociados, mientras que los demás lectores deban concurrir al establecimiento. Las personas que ocupan buena parte del día en el trabajo, argumentan los redactores, necesitan el libro en la casa. Por lo tanto, las condiciones de acceso a este beneficio no deben constituirse en un obstáculo.

Los responsables de la revista no reparan en las deficiencias de los modelos reglamentarios publicados como causal cierta o probable de la

27 Ibíd., p. LXXXVI 
repetición de cláusulas y requisitos indeseados. Sus percepciones los inducen a pensar que el problema radica en la energía que algunas las organizaciones ponen en la conservación de los libros, antes que en su difusión. En este sentido, observan: “QQué importa que un libro se destruya con el uso que de él se haga, si se consigue el fin que esta institución se propone, es decir, si sus ideas han quedado gravadas en miles de personas?". ${ }^{28}$ Preservar el material contra el uso negligente es un aspecto que ningún reglamento deja de señalar. Manchar, rayar, doblar, cortar; todas son acciones prohibidas y castigadas. Pero cuando se trata de los daños producidos por el desgaste natural del libro, las disposiciones eximen a los lectores de toda multa.

El siguiente testimonio, tomado de la memoria de gestión de la Biblioteca Popular de Rosario, expresa los resultados producidos por el préstamo de libros:

La institución de libros á domicilio, ha dado resultados moral y materialmente no esperados.

Desde Julio $1^{\circ}$ de 1873 en que se planteó la institución, hasta el 15 del corriente [mayo de 1874], se han llevado á domicilio 623 libros. De todo ese número solo 11 han sufrido deterioro un poco superior al que naturalmente debían tener por el uso. Solo un libro insignificante se ha perdido, que ha sido compensado con otro de igual valor y quizá de mas importancia: tres de aquellos, desencuadernados (...).

La regularidad del trato y la facilidad de devolucion de los libros, prueban el interés moral, la delicadeza y cultura de los sócios y de la sociedad en general del Rosario.

Lo sensible es que ningun no-sócio no ha llevado un solo libro á domicilio. ${ }^{29}$

Este fragmento muestra con nitidez cómo los redactores de la memoria se vieron sorprendidos al finalizar la evaluación anual. Sus conclusiones enseñan, además de los resultados cuantitativos, la desconfianza o el prejuicio que se extendía sobre los lectores respecto del buen trato que éstos pudieran dispensarle a los libros en el ámbito privado. En este tipo de declaraciones es donde mejor se comprende la insistencia de la Comisión por instituir lo que en aquel entonces era un servicio novedoso. Asimismo, es oportuno llamar la atención sobre el mencionado desinterés de los "no-socios". Esta constatación muestra que la perseverancia de los responsables del Boletín por propiciar facilidades para ese conjunto inestable de lectores no siempre tuvo el correlato deseado. Las razones de este distanciamiento

28 Boletín, op. ct., $1875, n^{\circ}$ 6, p. 64

29 Boletín, op. cit., $1874, n^{\circ} .5$, p. CLXVI-CVXVII 
pueden ser múltiples: desde diferenciaciones simbólicas que actúan como barreras implícitas, hasta una mala política en la elección de las obras.

El préstamo de libros a domicilio es, entonces, una pauta estratégica defendida con obstinación a lo largo del Boletín. Además de constituir el soporte operativo central de todo un proyecto cultural, los miembros de la Comisión entendieron que la lectura en las salas de las bibliotecas era un recurso no siempre practicable para estas organizaciones. Tres razones ayudan a comprender esta circunstancia. En primer lugar, estas bibliotecas debían orientar sus servicios a un lector ocupado buena parte del día en las actividades laborales. En segundo orden, los recursos de estas instituciones muchas veces no alcanzarían para costear los gastos necesarios para abrir las puertas entre cuatro y seis horas por día. Finalmente, no siempre las asociaciones contarían con un espacio propio para funcionar, lo que sin duda representaba un obstáculo.

La posibilidad de llevar los libros a domicilio también proporcionó una solución a la siempre problemática cuestión de los horarios de apertura. En este sentido, las bibliotecas populares adoptaron distintas alternativas conforme a los recursos disponibles y las proyecciones trazadas por sus organizadores. Los reglamentos brindan indicios de esta variabilidad. Las propuestas más ambiciosas planteaban atender a los lectores de lunes a viernes durante siete horas al día. Otras instituciones, más modestas en sus pretensiones, consideraron suficiente abrir dos o tres días a la semana por el término de cuatro o seis horas. La biblioteca de Humahuaca, por ejemplo, estipulaba prestar servicios los días jueves y domingos, entre las diez de la mañana y las cuatro de la tarde. Los horarios nocturnos también aparecen en las disposiciones como alternativa a las tradicionales bandas matutinas y vespertinas. Otros documentos, como la memoria de la Biblioteca de San Fernando, nos informan que las horas de la noche, más que una opción, eran una medida de gestión a tener en cuenta: “...convinar(sic.) los medios mas convenientes, para que la Biblioteca pueda estar abierta algunas horas a la noche, pues en las que de dia lo está (...), no son las mas adecuadas para que los artesanos concurran". ${ }^{30}$ La idea del lector como trabajador es una constante en el Boletín. Y esta es una de las circunstancias que la estrategia de la Comisión intentó salvar más allá de la realidad de cada una de las bibliotecas.

Como puede deducirse, la variabilidad estructural de las bibliotecas populares producidas por las mismas diferencias entre las asociaciones pue-

30 Boletín, op. cit., $1874, \mathrm{n}^{\circ}$ 5, p. CLV 
den llegar a ser importante. De allí que el servicio de préstamo a domicilio no sólo es un medio efectivo para ubicar la presencia material y simbólica del libro en los hogares, sino que también es el único modo de asegurar el encuentro entre las obras y los lectores.

\section{Instrucciones, ingenio y cultura: los libros del bibliotecario}

Todo préstamo de libros supone un conjunto de tareas preliminares que involucra, entre otros asuntos, la organización de un catálogo, el ordenamiento de las obras y la elaboración de un registro de préstamo. Estos aspectos nunca fueron atendidos con detenimiento por la Comisión, aun cuando existían manuales y tratados de biblioteconomía que pudieron ser tomados como referencia. ${ }^{31}$ Lejos de ofrecer una sección específica del Boletín que sintetizara algunas indicaciones y técnicas básicas, la información sobre estos temas se dispersa entre los diferentes reglamentos y algunas observaciones que pueden rescatarse de la memoria de la biblioteca de San Fernando, escrita por Juan Madero.

Señalemos, en primer lugar, que el derecho de nombrar al bibliotecario le asiste a cada asociación por intermedio de su comisión directiva. Asimismo, esta junta es responsable de fijar las obligaciones del cargo. En términos generales, no hay diferencias sustanciales entre las diversas disposiciones publicadas en la revista respecto de las funciones del bibliotecario. En una apretada síntesis, podríamos anotar: armar el catálogo, llevar los libros de préstamos, reservas y sanciones, confeccionar las estadísticas de circulación, mantener en orden los estantes, cuidar la civilidad en la sala de lectura, atender a los lectores con buena predisposición, recaudar las entradas de dinero por préstamos o multas y, finalmente, limpiar el local.

Entre reglamento y reglamento las distancias se ubican en el orden de las precisiones. En el caso de los deberes laborales del bibliotecario, algunos documentos se limitan a nombrar las tareas a realizar, mientras que otros también indican cómo es que éstas deben cumplirse. Los registros que describen las maneras de hacer nos ofrecen la posibilidad de entrever de qué forma estos anónimos trabajadores de la circulación de los libros hacían funcionar el sistema. La pregunta que nos ocupa ahora es: ¿qué nos dicen estas reglas del hacer?

El reglamento de la biblioteca popular de Baradero estaba provisto de una mínima guía acerca de cómo organizar el catálogo:

31 Esta cuestión fue advertida tempranamente por Amadeo Lucero en su trabajo Nuestras bibliotecas desde 1810. Buenos Aires: Coni, 1910, p. 190. 
[El bibliotecario debe llevar] Un catálogo de todos los libros con la numeracion sucesiva desde el 1 hasta el 100, etc. de los volúmenes que contenga cada seccion en que la Biblioteca se divida; poniendo la misma numeración en estampillas pequeñas en el dorso de cada volúmen. Las secciones serán designadas en el catálogo y en los estantes con el título correspondiente y número romanos. Estos números serán puestos en la estampilla de cada libro, repitiéndolos en todos los volúmenes que comprenda la sección designada por cada uno de aquellos números.

El catálogo contendrá además el precio en que cada obra hubiera sido tasada por la Comisión. Tendrá también una sección separada para los resúmenes y balances que se harán mensualmente, y al fin de cada año. ${ }^{32}$

Imaginemos a un bibliotecario de otra institución que está algo preocupado por organizar los libros en su biblioteca. A la mano no tiene más que la cita precedente y los restantes números del Boletín. Con estas herramientas y un poco de esfuerzo e ingenio comienza con la tarea. Las 123 palabras que sirven como instrucciones seguramente le son suficientes para comprender que el catálogo es un inventario de las obras existentes en los estantes, a la vez que un mapa para encontrarlas. Luego de haber entendido esta importante lección, constata que la biblioteca de la que se habla en el reglamento está dividida en secciones. Y aunque no sabe cuál es el criterio, retoma para su trabajo la clasificación temática correspondiente al catálogo de libros ofrecidos por la Comisión, esto es: filosofía; ciencias y sus aplicaciones a las artes y a las industrias; derecho, ciencia política, economía social y política; historia; geografía y viajes; literatura; educación; religión. ${ }^{33}$ Luego de examinar las obras, las separa según estas categorías. También confecciona unos carteles con los títulos de cada área temática y el número romano que le corresponde, por ejemplo: "I - Filosofía”. Asigna los lugares físicos y distribuye los volúmenes. En un cuaderno traza prolijamente las divisiones que copia de los anaqueles y comienza a registrar allí los títulos de todos los libros. Progresivamente asigna los números arábigos de identificación, escribe las estampillas y las pega en cada volumen. Asimismo, se cuida de anotar el precio de las obras en el catálogo, para luego poder acordar con los posibles infractores la tasa de la sanción. Finalmente, decide que los balances y las estadísticas se llevarán en un registro distinto. Un tiempo después, la misión está terminada.

La ausencia de indicaciones oficiales sobre cómo hacer un catálogo amplía los márgenes de la inventiva: combinaciones heterodoxas, elecciones

32 Boletín, op. cit., 1873, n 4, pp. LXXXVIII- LXXXIX

33 Boletín, op. cit., 1872, no. 1 
improvisadas o bien pensadas, usos singulares. El vacío que enseña el Boletín en esta parte de su discurso pedagógico es, cuanto menos, un descuido estratégico significativo. Sigamos adelante con el reglamento de la biblioteca de Baradero.

Además de organizar y actualizar el catálogo, el bibliotecario era responsable de registrar los préstamos a domicilio. Sobre este tema, varios reglamentos y apuntes de la Comisión indican los datos indispensables que debe llevar este formulario: nombre y dirección del lector, título de la obra, fecha de entrega y devolución, estado material y precio del libro. La particularidad que ofrece en este punto las disposiciones de la asociación de Baradero es - nuevamente- su modo instructivo de expresión:

Un libro de préstamo, dividiéndose cada renglon en casillas con la estension necesaria para designar lo siguiente, que será puesto en el encabezado de cada página. Apellidos y nombres (de los peticionarios) domicilio-fecha (de la entrega del libro.) Plazo-(para la devolucion del libro) $2^{\circ}$ (Plazo)-Precio-(del libro) Devuelto en (tal fecha) Observaciones ${ }^{34}$

Si un improvisado bibliotecario tomó alguna vez el reglamento que estamos estudiando en sus manos para ordenar una pequeña colección de libros en el estante y ponerlos a disposición de los lectores, entonces es probable que algo haya conseguido. Insistamos en un punto: las bibliotecas populares no se inscriben en una sociedad familiarizada con la cultura del libro y las liturgias de las bibliotecas. De allí que estas incipientes guías y otras anotaciones resulten sustanciales, aun cuando en apariencia prestar un libro sea una actividad menor.

En Baradero, el bibliotecario debe administrar otros tres libros. Uno de multas, que tiene por objeto "llevar la cuenta exacta de las que hay que cobrar, y las cobradas". ${ }^{35}$ Otro de reservas, para dejar constancia de los pedidos que pudiera tener una obra prestada. Finalmente, un libro índice de todos los anteriores. A diferencia de las indicaciones que citáramos para armar el catálogo y el registro de préstamo, para estos tres últimos caso no hay precisiones.

Cambiemos de documento. En la memoria de la Biblioteca Popular de San Fernando publicada en la quinta entrega del Boletín podemos encontrar un inmejorable ejemplo de la arquitectura de un catálogo completo. Su autor, Juan Madero, eleva el nivel de complejidad de los asientos bibliográficos

34 Boletín, op. cit., $1873, \mathrm{n}^{\circ} 4$, p. LXXXIX

35 Boletín, op. cit., $1873, \mathrm{n}^{\circ} 4$, p. LXXXIX 
respecto de lo conocido hasta ese momento en la revista de la Comisión. El cambio sustancial radica en el grado de descripción utilizado. A las ya conocidas áreas de autor y título, se añaden otras igualmente fundamentales, como la que corresponde a los datos de edición. Citemos el prolijo texto de Madero:

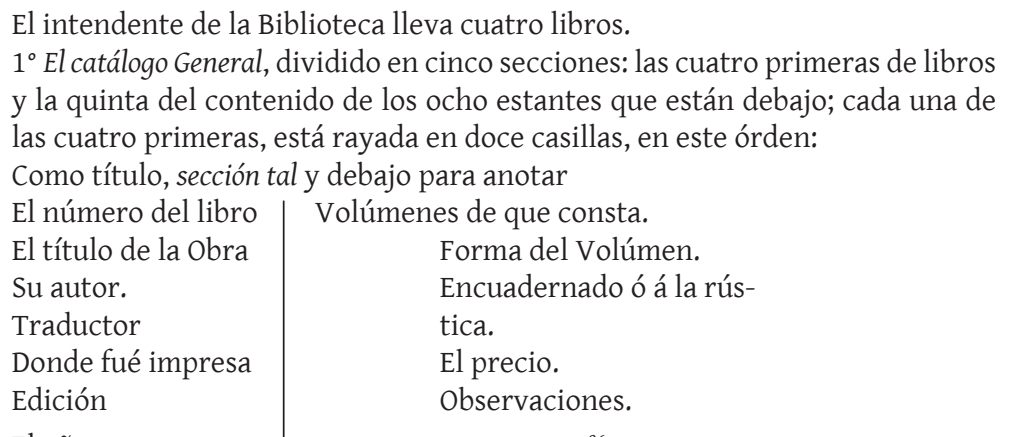

Este trabajo, inusitadamente minucioso para el contexto pedagógico del Boletín, enseña una captación bibliotecológica precisa del proyecto de lectura propuesto por la Comisión, e incluso lo sobrepasa. Y es que Madero no es la figura voluntariosa pero algo elástica y a veces incierta del amigo de la instrucción popular que el discurso republicano pregona. En todo caso responde en este aspecto con un encuadre ideológico funcional a la propuesta cultural oficial. Él, como otros personajes que sí son decididamente silenciosos en esta historia, procuró organizar una biblioteca para su comunidad. Esto es suficiente para ubicarlo en las coordenadas precedentes. Del lado de las maneras de hacer, de las formas de concreción, se sitúan las distinciones sobre las cuales es posible construir trayectorias institucionales duraderas. Esto es: el rigor presente en la elaboración del catálogo revela, ante todo, compromiso y dedicación con las tareas bibliotecarias. En segundo orden, se observa inequívocamente una relación profunda con la cultura del libro en general, y con el objeto mismo en particular. Para catalogar una obra en el modo en que se sugiere es necesario conocer la materialidad del libro, saber explorar sus partes. El conocimiento de los detalles bibliográficos y su probable importancia no es natural a cualquier lector devenido en bibliotecario. Por ejemplo: ¿quién puede juzgar que la identidad del traductor es un dato ineludible? ¿Qué reglas culturales deben manejarse para cristalizar un juicio de este tipo? ¿En qué lectores se piensa

36 Boletín, op. cit., 1874, n5, p. CLIII 
como horizonte cuando se cree conveniente dejar constancia de esta información? En conjunto, la exhaustividad que promete el catálogo de la biblioteca de San Fernando nos permite insistir en la muy deficitaria perspectiva técnica del Boletín. La limitada oferta de explicaciones deja el quehacer bibliotecario liberado a la disponibilidad de capital cultural de los interesados, siempre sujetos a la disposición de tiempo y recursos para concretar la producción creativa.

En la biblioteca popular de San Fernando el trabajo con los libros no termina con El catálogo General. Según las indicaciones de Madero, a la mano de los lectores hay otra fuente de acceso a las obras:

$2^{\circ}$ El catálogo alfabético, que solo contiene:

Número de la seccion

Número del libro

Título del libro

Nombre del Autor

“...a disposición del público" este pequeño libro para buscar los otros Que se coloca sobre la mesa de lectura á disposición del público. ${ }^{37}$

libros. El catálogo no es sólo una herramienta que opera el bibliotecario; también es una pieza de consulta para los usuarios. A la sala de lectura, entonces, van a cazar furtivamente los lectores - la expresión corresponde a de Certeau-. Pero la espesura de la biblioteca es tal que ya no les permite el acecho sin un mapa. Entre las historias y sus recreadores media ahora un trabajo sigiloso. El resultado es un camino de renglones con nombres y títulos que se murmuran y recorren con el dedo índice.

Un tercer libro se prepara en la biblioteca San Fernando. Este texto reúne todas las obras de la biblioteca según sus temas. Escuchemos nuevamente el detallado relato de Madero:

También se ocupa la Comisión de hacer otro catálogo, por materias, lo que no pudo realizar desde el principio, por el órden y retardos con que fueron recibidos los libros.

Formarán la primera sección los libros de:-Culto, Moral, Filosofía, Política, Derecho, Legislación.

La segunda:-los de literatura, Poesia, Teatro, Romances, Historia, Biografia, Viajes, Bellas Artes.

La Tercera:-Los de ciencias, matemática, Física, Medicina, Industria y Agricultura.

La Cuarta:-Los folletos, periódicos y demás publicaciones lijeras.

La quinta-Los diarios de sesiones del Congreso y Legislatura Provincial, Registro Oficial, Registro estadístico, Censo, Memorias Ministeriales, Mensajes, \&. ${ }^{38}$

37Boletín, op. cit., $1874, \mathrm{n}^{\circ}$ 5, p. CLIII

38 Ibidem, p. CLV 
Para organizar este catálogo, es decir: para agrupar los libros según un orden temático se requieren criterios culturales sólidos. Una lista alfabética puede organizarse sin mayores dificultades. Pero una clasificación por áreas exige una intervención intelectual de rigor, pero también saber tomar atajos. Para conocer con qué materia se identifica mejor un texto sin leerlo en su totalidad es necesario manejar correctamente el dispositivo material del libro: portada (título, autor, edición, fecha, etc.), índice, introducción, prólogo, colofón, etc. De otra manera, la tarea sería infinita.

En las bibliotecas, los libros recorren un camino antes de llegar a los lectores. Del conjunto de pautas que con cierta dificultad pueden extraerse de la espesura del Boletín, se comprende que este itinerario se inicia con el pedido de una partida de obras. Como los viajes no son cosa fácil en el siglo XIX, hay que ser pacientes con la llegada de la encomienda. Cuando los libros están en la biblioteca, lo primero es controlar las existencias de acuerdo a la solicitud efectuada. Luego se clasifican las obras según las secciones de la biblioteca y se registra la entrada en los catálogos. Se pegan las signaturas topográficas. Se marcan los ejemplares con el sello de la biblioteca y quedan listos para el préstamo. Cómo organizar cada uno de estos pasos es una materia pendiente en la revista de la Comisión. Este es su déficit más notable.

\section{Epílogo}

Al iniciar este trayecto, hemos señalado la enérgica crítica que la Comisión hiciera contra la Sociedad Tipográfica Bonaerense porque su biblioteca no ofrecía llevar los libros a domicilio a sus afiliados. No obstante, observamos que más que una reprimenda particular, los redactores del Boletín estaban procurando instituir nuevas significaciones respecto de la tradición bibliotecaria nacional. Y la densidad simbólica de este pasado se condensaba para ellos en una única institución: la Biblioteca Pública de Buenos Aires. De manera que la intervención de la Comisión se construye como una alternativa a la manera de ser y hacer de aquel establecimiento. Para iluminar estas diferencias, para intentar comprender desde fuera el espesor de esta producción de sentido, introducimos las diferencias que separaban a Sarmiento de Quesada respecto del rumbo que la biblioteca porteña debía asumir en 1877. El resultado de esta estrategia nos dejó una constatación: la idiosincrasia de una biblioteca popular estaba constituida por una faz conceptual, identificada con la idea de ampliación de las fronteras de la lectura, y otra operativa, asociada a una manera distinta y novedosa de entender los servicios de las bibliotecas y su relación con los lectores. En la encrucijada 
de esas dos dimensiones se localiza la obligación primordial de la Comisión, a saber: elaborar las reglas del hacer bibliotecario. En este sentido, los redactores del Boletín se preocuparon por difundir dos servicios fundamentales: el acceso libre y gratuito a la lectura en la biblioteca junto con el préstamo de libros a domicilio a cambio de una cuota solidaria. Este último beneficio constituía una verdadera novedad bibliotecológica. Para enseñar las bases funcionales de estas prestaciones, la Comisión reprodujo en su revista una serie de reglamentos de bibliotecas populares en funcionamiento. Mediante esta estrategia pedagógica, se esperaba que los lectores devenidos en bibliotecarios también pudieran ordenar los quehaceres cotidianos de la institución. No obstante, el análisis de los reglamentos publicados en el Boletín muestra que para realizar estas actividades laborales se necesitaba de un complemento técnico básico. La ausencia de una sección dedicada a brindar instrucciones sobre cómo, por ejemplo, organizar un catálogo, es una de las principales falencias de la revista. Sólo apelando a otros registros documentales, como la memoria de la biblioteca de San Fernando, un lector pudo formarse una imagen de la tarea. No obstante, el esfuerzo que implicaba la detección y el estudio de pasajes claves es de por sí un síntoma de los problemas editoriales del Boletín en este aspecto.

Con todo, aquello que podemos conocer a partir los reglamentos de las bibliotecas populares y los restantes registros documentales analizados no dista, en general, de las constataciones que otros estudios han destacado en el contexto de América Latina. ${ }^{39}$ Esto es: idiosincrasias y rutinas institucionales, tareas de los bibliotecarios, obligaciones y derechos de los lectores, usos y accesibilidades al material bibliográfico, etc. Un acercamiento de este tipo ayuda a comprender la complejidad que envuelve a los procesos históricos de las bibliotecas, pero también nos aproxima a las prácticas de lectura que contribuyen a cimentar y modificar en el largo de los años.

Por otro lado, este estudio aporta una singularidad que cabe destacar: la mediación editorial operada por la Comisión. Esta intervención es una parte central de la propuesta investigativa que sostenemos. El collage de registros informativos que intercala el Boletín exigió explorar dos senderos entrecruzados: de un lado, el que lleva a inventariar la propuesta bibliotecológica de la Comisión; de otro, el que conduce a recapitular las apropiaciones

39 Nos referimos a los ya citados trabajos de Alejandro Parada y Claudio Denipoti, cuyas investigaciones y reflexiones han contribuido con la apertura de un camino investigativo que no se reduce al inventario y la descripción de los reglamentos y los estatutos, sino que constituye una búsqueda por entender los cruces y las trayectorias de los lectores, los libros y las bibliotecas. 
que las bibliotecas hicieron en ese terreno. Esto último también incluye una mirada sobre los quehaceres bibliotecarios implicados en la unión entre el mundo del libro y el de los lectores. En su conjunto, estos pliegues nos permitieron asomarnos a la funcionalidad de las bibliotecas populares.

Lo dicho sugiere que aquello que denominamos como "hacer las reglas del hacer" está atravesado por dos lógicas mutuamente vinculadas. Una de ellas es la que imprime la Comisión, mediante la selección y la publicación de reglamentos de bibliotecas populares en funcionamiento. Este repertorio de textos, aun considerando los descuidos que obligaron a más de una aclaración, permite formarnos una imagen de la idea que esta agencia estatal tenía de lo que debía ser una biblioteca popular. Cada elección editorial de la Comisión confirma en líneas generales su pensamiento bibliotecológico. Ahora bien, la apelación sistemática a registros documentales producidos por las asociaciones de lectores hace que el Boletín no sólo sea el testimonio tangible de una estrategia, sino también el escenario de las apropiaciones tácticas. ${ }^{40}$ En el contexto de un vocabulario elaborado y controlado por la Comisión, los organizadores de las bibliotecas van escribiendo sus propias frases. Los desplazamientos son observables en las diferencias que se extienden entre los reglamentos aparecidos en la primera entrega de la revista y las siguientes. Si bien estas disposiciones responden a una misma concepción global, las variaciones se acomodan progresivamente a las posibilidades materiales y a las trayectorias culturales inmanentes a cada asociación. Ejemplos de ello son las notables diferencias propuestas para los días y los horarios de apertura.

El espacio dedicado en el Boletín a las reglas del hacer bibliotecario es, entonces, un terreno compartido por la Comisión y por un conjunto de asociaciones ideológicamente afines. El itinerario de esta producción de sentido se inicia con una propuesta estratégica fijada por la posición editorial de revista, continúan con las apropiaciones tácticas de las bibliotecas populares y finaliza cuando algunas de estas relaboraciones retorna al Boletín para constituirse en parte de la estrategia.

Una vez captado el modo en que opera esta mediación editorial, es posible asir la faz operativa prevista para las bibliotecas populares. En este sentido, los reglamentos dejan de aparecer como simples figuras normativas de las que sólo cabría inventariar los objetivos programáticos que contienen, y nos ayudan a comprender algo de aquellas prácticas perdidas en el tiempo. Asimismo, otros registros narrativos - como las memorias de las bibliotecas

40 Certeau, Michel de. op. cit. 
de San Fernando o Rosario- brindan un complemento informativo insustituible para conocer las rutinas bibliotecarias implicadas en la construcción de estos espacios de lectura. Instituidas entre las reglas y el quehacer diario, las bibliotecas populares se les presentaron a los lectores como lugares institucionalizados, como series ordenadas de libros y de liturgias de las que pudieron hacer uso. De qué modo los lectores transitan este terreno es una cuestión por indagar.

Artigo recebido para publicação em: 18/12/2013 Artigo aprovado para publicação em: 28/04/2014 